Jane Nichols

\title{
Library à la Carte \\ Research and course guides made to order
}

W

ith increasing demands on their time, librarians seek speedier, easier ways to create library course pages and subject research guides. Many libraries have turned to LibGuides, LibData, and other content management systems (CMS) to meet this need. ${ }^{1}$ Add to this mix, Library à la Carte, formerly Interactive Course Assignment Pages (or ICAP) Tool. Created by librarians and a programmer at Oregon State University (OSU) Libraries, Library à la Carte is a CMS originally designed to create course pages. Library à la Carte was recently enhanced to build subject pages. This open source tool is freely available to all libraries.

\section{Background}

In 2005, we focused on creating library course pages as a strategy to alleviate students' frustration with finding and using OSU Libraries resources. Because our current pages were made using a static HTML template, this was a time-consuming and challenging endeavour. Moreover, librarians who wished to include traditional library content, such as library catalogs and databases, along with dynamic content, like RSS feeds, didn't have an easy way to do so, nor did they have time to learn. We wanted our pages to be more aesthetically pleasing, easier to scan, and content more easily located than what long lists of links allow. Without a Web site driven by a CMS or a Web programmer to develop such a site, librarians were prevented from creating dynamic pages or featuring dynamic content. Clearly it was time for a new approach.

We evaluated available content management applications, such as Ithaca College's
Subjects Plus, but did not find a good match for our environment. ${ }^{2}$ We wrote a use case scenario and discussed with library administration the need for a Web programmer for our next steps. The use case scenario described the content and functionality we wanted to include in course pages. Faculty and students tested a sample template and design of the pages. Library administration assessed the library's need as a whole for a programmer. After these steps were completed, the administration had enough information to decide in favor of hiring a programmer, a key turning point in the process. The programmer was able to build a beta CMS in six months using Ruby on Rails, an open source Web application development framework that enables rapid programming. ${ }^{3}$ Librarian feedback was incorporated through usability testing and paper prototyping, which fostered familiarity with the system and eventual buyin. Using the first incarnation of the tool, librarians made more than 50 course pages in fall $2007 .^{4}$

\section{Course pages}

The first version of Library à la Carte, the ICAP tool, enabled librarians to create, manage, publish, and coauthor course Web pages with greater ease then when using HTML and Web page editors like Adobe DreamWeaver or Contribute..$^{5}$ Librarians collaborated with faculty to contribute content to the pages and

Jane Nichols is social sciences/humanities librarian at Oregon State University, e-mail: jane.nichols@ oregonstate.edu

(๑) 2009 Jane Nichols 
promote their use. Including both librarian and faculty contact information demonstrated that a relationship existed between the two, showed that instructors approved the content, and reinforced the value of the pages to students. When possible a link to course assignments was included for students' convenience and to reinforce the guides' purpose.

The ICAP tool made many desired features available to librarians. Core library content could be placed alongside Web 2.0 content, such as social networking badges and Delicious tag clouds. Librarians who wished to include dynamic content in their

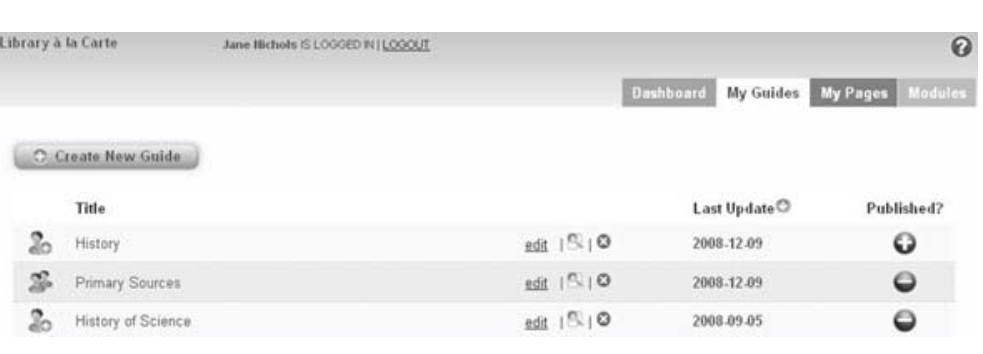

Subject guides in Library à la Carte evant to students. our subject guides rather than doing away with them. We sought to "find techniques to make subject guides ... more contextual to students." We hypothesized that redoing subject guides using the features and functionality available in our course guides would make them more appealing and rel-

Besides the enthusiasm for employing the ICAP tool to make subject guides more relevant to students, OSU librarians agreed with William He m mig's 2005 findings about subject guides' pedagogical value. Subject guides (or pathfinders) have been traditionally could do so with RSS feeds and book jackets pulled in from LibraryThing. To provide immediate searching, a search box featuring OSU Libraries' metasearch software, Libraryfind, was available. A chat widget connected students to librarians. A modular design was used so students could quickly scan the page and identify needed research tools and information. Gathering feedback on the pages was now an option through the use of a polling widget. On the library homepage, the course pages were more readily found under the label "Get Help with a Course." All of these seemingly small changes added up to provide students a visually engaging and clear path to resources to help them complete their assignments. Thanks to an easy-to-learn interface, librarians quickly became facile with the tool and wanted to use it for other purposes. Redoing subject research guides was at the top of the list.

\section{Subject pages}

Our subject guides ranged from neglected pages to static HTML files sorely in need of some spice. Moreover, usage statistics for our guides showed low use. Despite these challenges, we decided to inject new energy into "intended for users engaged in the beginning stages of the search process" and are "designed to facilitate the search process." We felt that subject guides fill an instructional gap for our primary audience-students-because the guides are a starting point for doing university-level research in an academic discipline. Our experiences with students unfamiliar with disciplinary resources and search strategies for finding and using disciplinary information encouraged us to renovate our subject guides.

Before recreating the guides using the ICAP tool, librarians worked with the programmer to identify needed changes to the CMS. We wanted to take advantage of the existing features and functionality available from the ICAP tool, but these didn't meet all of the guides' needs. OSU librarians started to determine new features and functionality by identifying common content they wanted in the subject guides. The list consisted of standard library content, such as e-journals, databases, catalogs, Web sites, and reference works. Additional pinpointed items included a librarian profile (and chat widget if desired), introductory text, quick links, and date of last update. 
Librarians also identified new functions for the tool. We sought to showcase content related to the subject guides, such as OSU departments and centers as well as other relevant course and subject guides. Instead of sticking with a table of contents in list format, we wanted a new way to navigate to the guides. Perhaps the most desired change was making the text of the guides more scannable and visible so students could more readily recognize what they needed, so we decided to use tabs to categorize content and a modular design. Librarians had wanted a way to foster discussion or comments among users of the course guides. This wish resurfaced as we discussed changes to the tool for the subject

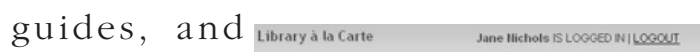
our programmer met this need by developing a commenting module. The comments module functions like blog comments where users can enter their name, e-mail, and comment.

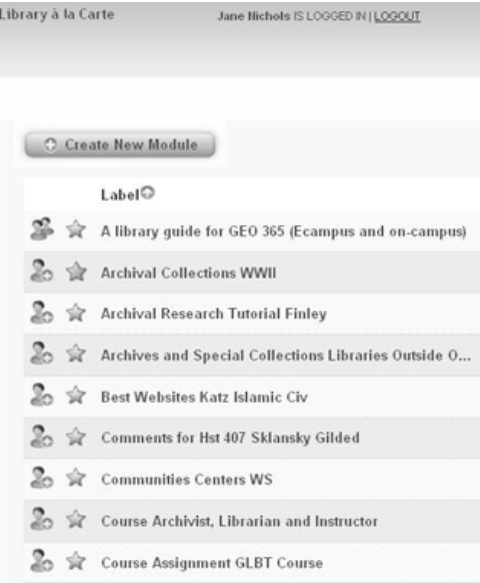

Library à la Carte Modules

\section{From ICAP tool to Library à la Carte: Create course or subject guides}

As the ICAP tool became Library à la Carte, modules took center stage as they could be placed on either course pages or subject guides. Core library resources (catalogs, databases, journals, reference works), images, RSS feeds, a chat widget, and custom search boxes-all are relevant to both course and subject guides. Creating modules to be posted to either type of guide offers a workflow where librarians can write content once and reuse as needed. Since librarians may still want to customize reused content, they can do so.

Corollary to the shift towards modules

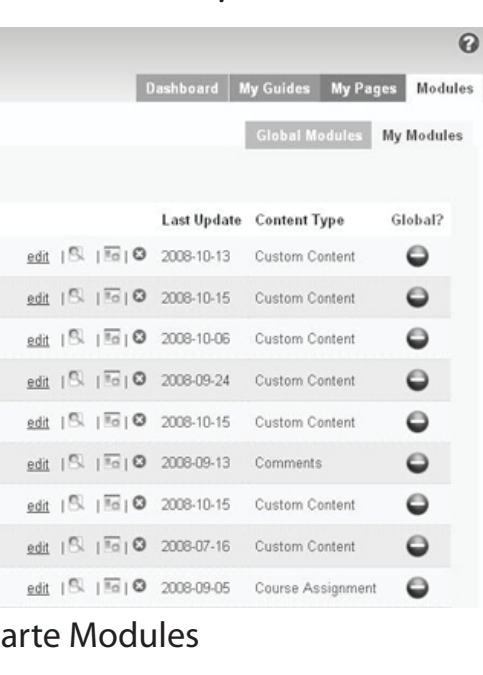
was an interest in sharing modules among librarians. Two forms of sharing are built into Library à la Carte. One type of sharing allows two or more librarians to coauthor a module and place it on Name and e-mail were made optional to accommodate users who prefer to anonymously leave their remarks. The librarian can choose to display three-to-eight comments.

A few of the changes we sought impacted course pages. After using the ICAP tool for a few terms, librarians noticed that students and faculty wanted to view course pages from previous terms. To solve this, the programmer built an archive function for the course pages. At this point, there is not a strong need to apply the archiving function to subject pages. Library à la Carte automatically displays a related course or subject guides section on both types of guides. Course guides show related subject guides, and subject guides link to both relevant course and subject guides. We hope these links will promote guides' use. their own or their shared pages. A typical example is if multiple librarians post the same plagiarism module on their respective course guides. Another type of sharing is when a librarian makes a module "global." Here, a module is created and marked "global." Then librarians copy, customize, and post it to their guides. Other librarians can save the module to their pages and then amend the content as they wish.

\section{Portal pages}

Our programmer encouraged us to let Library à la Carte generate a portal page for subject guides, which it was already doing for course guides. Librarians agreed and took this opportunity to reconsider how to improve both portal pages. Several additional features were incorporated. Users now have more ways 
to discover pages.

They can browse alphabetically or by tag cloud. The tags are assigned by librarians when they make their guides. Also, a search box lets users do keyword searches for either type of guide. The

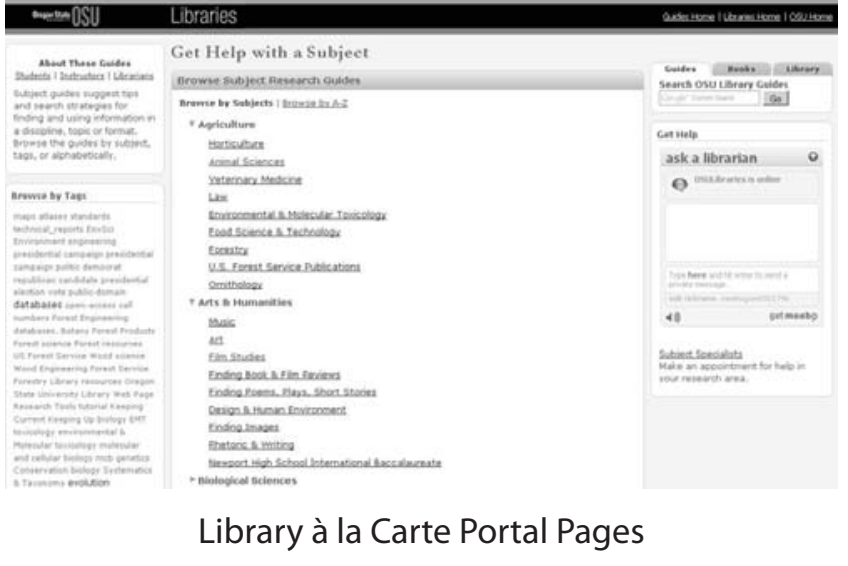
writing content rather than programming.

\section{Notes}

1. Edward M. Corrado et al., "Free and Open Source Options for Creating Database-Driven Subject Guides" The programmer used a Google API to create a custom search box so users can search guides, the library catalog, and the library Web site. On the portal page for courses, students can also browse by broad academic subject, such as Humanities, and filter by department. Both portal pages offer an overview of the guides' purpose to students, faculty, and librarians. Credit goes to the University of WisconsinMadison libraries for the idea of including this section. ${ }^{8}$ On each portal page, a section contains a chat widget that connects users to reference staff links to subject specialists.

\section{Preliminary assessment results}

When librarians rolled out course pages produced using the ICAP tool, they received positive anecdotal feedback from faculty and students. An assessment of the course guides created with Library à la Carte is planned for fall 2008-winter 2009. User feedback for the subject guides will be collected on an ongoing basis. Librarians are pleased with Library à la Carte and the guides they can make with it. They especially like the contemporary look of the pages, that they can embed social software, and the flexibility of the tool.

\section{Conclusion}

Libraries and librarians are increasingly pressed to work efficiently and effectively. Library à la Carte joins other software and services that help librarians make course and subject guides more quickly. For OSU librarians, having the tools needed to quickly and easily create Web content means they can use their time and skills to focus on

Code4Lib Journal 2 (2008), journal.code4lib. org/articles/47 (accessed April 9, 2009).

2. Subjects Plus, Ithaca College, www. ithacalibrary.com/subsplus/ (accessed April 9, 2009).

3. Rails, 37Signals, www.rubyonrails.org/ (accessed April 9, 2009).

4. Kim Griggs et al., "Creating Interactive Course Assignment Pages: The OUS Libraries ICAP Project," Integrating Library Resources (paper presented at the Coalition for Networked Information Task Force Meeting, Washington, D.C., Fall 2007), www.cni. org/tfms/2007b.fall/Abstracts/PB-integratinggriggs.html (accessed April 9, 2009).

5. "The ICAP (Interactive Course Assignment Pages) Publishing System," The Code4Lib Journal 2 (2008), journal.code4lib. org/articles/63 (accessed April 9, 2009).

6. Brenda Reeb et al., "Students, Librarians, and Subject Guides: Improving a Poor Rate of Return," portal: Libraries and the Academy 4, no. 1 (2004):126, muse.jhu.edu/login?uri= /journals/portal_libraries_and_the_academy /v004/4.1reeb.html (accessed April 9, 2009).

7. William Hemmig, "Online Pathfinders: Toward an Experience-Centered Model," Reference Services Review 33, no. 1 (2005): 75.

8. University of Wisconsin-Madison Libraries Research Guides: What are Research Guides?, University of Wisconsin-Madison Libraries, www.library.wisc.edu/researchguides/ (accessed April 9, 2009).

9. For those interested in learning more about Library à la Carte, see alacarte.library. oregonstate.edu/. z 